\title{
Site-specific assessment of wind turbine residual life and health status
}

\author{
Ri Yang Guo ${ }^{1 *}$, Wei $\mathrm{Li}^{1}$, Hui Xia ${ }^{1}$, Jiang Zhe Feng ${ }^{1}$, and Huai Hui Ren ${ }^{1}$ \\ ${ }^{1}$ Longyuan (Beijing) Wind Power Engineering Technology Co., Ltd., Xicheng District, Beijing, China
}

\begin{abstract}
At present, some $600 \mathrm{~kW}$ and $750 \mathrm{~kW}$ wind turbines put into operation earlier in China have exceeded their 20-year design life. For these turbines, the safety, reliability and economy of these turbines are usually evaluated in a reasonable way, so as to formulate life extension or decommissioning strategies to maximize economic benefits. Referring to the current international standards and guidelines, this paper takes a wind farm in South China as an example to evaluate the remaining life and state of the turbines. The external environment data of the met mast is extrapolated to the turbine site, and the load simulation is carried out based on the wind turbine model. The fatigue load set of the turbines under the design load condition and the site-specific load condition is obtained. The possible fatigue damage in the historical operation period is calculated. Combined with the linear damage accumulation theory of Miner, the fatigue of each turbine in the site is obtained by load analogy. The final P90 life is obtained by analyzing the uncertainty factors introduced in the assessment of residual life and health status.
\end{abstract}

\section{Introduction}

The design life of wind turbines is usually 20 years. According to statistics, there are more than 11000 wind turbines under MW level in operation in China, with a capacity of about $8700 \mathrm{MW}^{[1]}$. For turbines approaching or reaching the design life, due to large design margin or better operation environment than the design conditions, the turbine is still in good operation state after 20 years of operation, and the life of the whole turbine and parts does not reach the design life. Therefore, in order to make full use of the existing resources and maintain the sustainable profitability of the project, the old turbines can still maintain operation under some limited conditions ${ }^{[2-3]}$. However, in consideration of the extreme events that the turbine may experienced during the historical operation period, the possibility of inherent fatigue damage of components, and the change of site environment, in order to ensure safe and reliable operation, it is necessary to carry out residual life and health assessment for the turbine and parts.

The load in the operation of wind turbine mainly comes from the turbine itself and the external environment, in which the external environment is mainly the wind condition, which is transformed into the transmission of wind load in the turbine and the foundation. Therefore, through the establishment of wind turbine and site environment model, the external environment of wind turbine and the static and dynamic load in operation, the load of the turbine and the fatigue life can be estimated. Therefore, this method can be used to predict the fatigue damage and residual life of the turbine. At the same time, combined with condition monitoring, through reasonable model analysis, it can predict the possible failure of the turbine and reduce the risk of failure ${ }^{[4-5] \text {. }}$

\section{Relevant standards for turbine residual life assessment}

At present, the wind turbine design is mainly implemented according to the IEC61400-1 standard. The residual life assessment of wind turbine is similar to the turbine design process. Due to the large difference between the old and the current standards, it's needed for selection in the residual life assessment. At present, IEC standards for the extension of wind turbine life (IEC 61400-28) are under published. Among the published standards and guidelines, the representative standards are DNVGL-ST-0262: Lifetime extension of wind turbines and ANSI/UL 4143: Standard for wind turbine generator life time Extension (LTE) standards.

The standards mainly focus on the basic conditions, scope, methods and results evaluation of the residual life evaluation of the turbine. For the residual life evaluation of old turbines, both standards are recommended to be carried out by "theoretical calculation + state check". Among them, the theoretical calculation mainly focuses on the analysis of fatigue load in the historical operation period, and the residual life of the turbine is calculated by fatigue damage model; the status inspection mainly focuses on the current basic operation state of the turbine. According to the principle of turbine failure, the general cover turbine visual inspection, vibration and oil detection, non-destructive testing, etc. ${ }^{[6-7]}$. In UL 4143,

\footnotetext{
* Corresponding author: ${ }^{\text {ariyang.guo@ }}$ chnenergy.com.cn 
the recommended evaluation contents mainly include modeling calculation of external environment conditions, analysis of operation conditions, turbine model establishment and residual service life calculation, turbine inspection and LTE risk analysis ${ }^{[7]}$.

This paper takes a wind farm as an example, according to the above standards and combined with the IEC 61400-1 standard, analyzes and calculates the residual life of the wind farm, including external environment condition analysis, historical operation data analysis, residual life calculation analysis and uncertainty analysis. The wind farm is located in South China, the planned area is mountainous region with steep terrain. The turbines are arranged along the southeast ridge with an altitude of about $1300 \mathrm{~m}$. The wind farm is composed of 33 stall type turbines, the main technical parameters of the turbines are shown in Table 1.

Table 1. Main technical parameters of the turbine.

\begin{tabular}{|c|c|c|c|c|c|}
\hline Parameter & Value & Unit & Parameter & Value & Unit \\
\hline Land / Sea & land & - & Hub diameter & 4.8 & $\mathrm{~m}$ \\
\hline Grade / Category & $\mathbf{S}$ & - & Impeller speed & $18.0 / 27.0$ & $\mathrm{rpm}$ \\
\hline Power regulation & Stall & - & Generator speed & $1008 / 1512$ & $\mathrm{rpm}$ \\
\hline Rated power & 600 & $\mathrm{~kW}$ & Gearbox speed ratio & 56 & - \\
\hline Number of blades & 3 & - & Impeller + Hub mass & 14600 & $\mathrm{~kg}$ \\
\hline Rated wind speed & 13 & $\mathrm{~m} / \mathrm{s}$ & $\begin{array}{c}\text { Nacelle } \\
\text { mass }\end{array}$ & 20800 & $\mathrm{~kg}$ \\
\hline Cut in wind speed & 4 & $\mathrm{~m} / \mathrm{s}$ & Tower quality & 42000 & $\mathrm{~kg}$ \\
\hline Cut out wind speed & 25 & $\mathrm{~m} / \mathrm{s}$ & $\begin{array}{c}\text { Natural frequency of } \\
\text { tower }\end{array}$ & 0.669 & $\mathrm{~Hz}$ \\
\hline Rotor diameter & 43 & $\mathrm{~m}$ & Impeller speed & $18.0 / 27.0$ & $\mathrm{rpm}$ \\
\hline Hub height & 46 & $\mathrm{~m}$ & Generator speed & $1008 / 1512$ & $\mathrm{rpm}$ \\
\hline
\end{tabular}

\section{External environmental conditions analysis}

For a wind farm composed of multiple turbines, due to the influence of geographical environment and turbine arrangement, the wind conditions of each turbine in the wind farm are quite different. For the residual life assessment of each turbine in the wind farm, the wind condition data at the location of the turbine should be obtained $^{[8]}$. The data that can be used to determine the wind data at the hub height of the site include the turbine SCADA data, met mast data, adjacent weather station data, global atmospheric data, etc. The most direct way to obtain the turbine location is to use the nacelle wind measurement system data, but the wind data collected by the wind measurement system is greatly affected by the turbine wake, and can not be directly used as the wind data of the turbine at this site. One feasible way is to adopt a method similar to the micro site selection of wind farm, that is, to conduct quantitative extrapolation analysis and calculation on the wind condition distribution of each turbine in the wind farm through the met mast data. The calculation model needs to consider the site geographical environment, turbine layout, wake model, tower shadow effect, etc. ${ }^{[8]}$. Among them, for the mountainous complex terrain, special attention should be paid to the influence of wind turbine wake on the wind conditions at the location of the turbine.

In this case study, Openwind software is used for site wind condition modeling. In order to fully consider the seasonal change of wind condition and reasonably evaluate the wind condition in the historical operation period, the effective wind measurement data in the wind farm should be obtained as much as possible (the measurement and statistics period of this case is 3 years).
After quality control, the data is revised as the input condition of site wind condition after the representative year correction, and Combined with the detailed information of terrain altitude, inflow angle, roughness and so on, the mesoscale model of the wind farm area is established, and the horizontal extrapolation of wind conditions from the met mast to the hub height of each turbine location is completed. In addition, the effects of the wake of each turbine and wind direction on wind speed distribution, effective turbulence intensity, wind shear, air density and inflow angle are also calculated.

According to the IEC61400-1 standard, the wind farm in this case meets the characteristics of complex terrain, and the influence of wake should be considered. The two wake models in Openwind are Eddy Viscosity and DAWM-EV. In this case, we use DAWM-EV model, which is the combination of standard eddy viscosity model and DAWM wake model. Based on the Frandsen theory, the DAWM model takes the wind turbine of the wind farm as the array model to consider the roughness. The model is separated from the coupled basic wake model (park or EV), and is combined by using the maximum roughness effect and the standard wake effect. Roughness exerts resistance on the atmosphere, which leads to the downstream change of atmospheric boundary layer structure, especially the decrease of free flow velocity at the hub height. The equivalent roughness of wind farm is as follows:

$$
z_{00}=h_{H} \exp \left(-\frac{\kappa}{\sqrt{c_{t}+\left(\kappa / \ln \left(h_{H} / z_{0}\right)\right)^{2}}}\right)
$$




$$
c_{t}=\frac{\pi}{8 s_{d} s_{c}} C_{T}
$$

$h_{H}$ : hub height, $\kappa:$ von Karman constant, $z_{0}$ : Environmental roughness between turbines, $c_{t}$ : distributed thrust coefficient, $C_{T}$ : turbine thrust coefficient, $s_{d}, s_{c}$ : average downwind and crosswind spacing of impeller diameter.

After defining the equivalent roughness, the wind speed influence at hub height is estimated under the assumption that the constant ground speed is logarithmic distribution with the atmospheric boundary layer. The results are approximately expressed as follows:

$$
\frac{v_{H}^{\prime}}{v_{H}}=h\left(\frac{z_{00}}{z_{0}}\right)^{0.07} \frac{\ln \left(h_{H} / z_{00}\right)}{\ln \left(h_{H} / z_{0}\right)}
$$

$v_{H}^{\prime}, v_{H}$ : wind speed at hub height inside the array and upstream of the far end.

After calculation, the average wind speed and turbulence intensity of each wind turbine affected by wake are obtained. For single turbine wind speed calculation, 84 sectors are considered in the analysis, and the corresponding wind speed distribution in each sector is calculated in Table2. The average wind speed affected by wake is used to calculate the life extension factor (LTE) of wind farm. For the calculation of turbulence intensity of single turbine, the wind speed turbulence intensity data of met mast is used, and the influence of wind farm layout is considered (the wake effect is estimated by Frandsen method). The average turbulence intensity calculated at $15 \mathrm{~m} / \mathrm{s}$ is shown in Table 3 . According to the layout of wind farms and nearby wind farms, the turbulence intensity of each sector includes wake effect.

Table 2.Average wind speed of wind farm affected by wake[m/s].

\begin{tabular}{|c|c|c|c|c|c|}
\hline Turbine & Speed & Turbine & Speed & Turbine & Speed \\
\hline F01 & 5.0 & F02 & 5.3 & F03 & 5.4 \\
\hline F02 & 5.6 & F05 & 5.7 & F06 & 5.7 \\
\hline F03 & 5.8 & F08 & 5.8 & F09 & 5.5 \\
\hline$\ldots$ & $\ldots$ & $\ldots$ & $\ldots$ & $\ldots$ & $\ldots$ \\
\hline
\end{tabular}

Table 3.Effective turbulence intensity of wind farm[\%].

\begin{tabular}{|c|c|c|c|c|c|}
\hline Turbine & $\mathrm{I}_{\text {ref }}$ & Turbine & $\mathrm{I}_{\text {ref }}$ & Turbine & $\mathrm{I}_{\text {ref }}$ \\
\hline F01 & 20.36 & F02 & 19.46 & F03 & 19.09 \\
\hline F02 & 18.30 & F05 & 17.14 & F06 & 16.61 \\
\hline F03 & 16.51 & F08 & 18.61 & F09 & 19.41 \\
\hline$\ldots$ & $\ldots$ & $\ldots$ & $\ldots$ & $\ldots$ & $\ldots$ \\
\hline
\end{tabular}

The site condition data (roughness) and met mast data are processed, and the wind shear coefficient is calculated by Openwind. For the calculation of a single turbine, 12 sectors are considered in the analysis, and the corresponding shear coefficient in each sector is calculated. Table4 describes the average wind shear coefficient representing the whole wind farm. For the air density calculation, the corresponding air density value is extracted from the met mast data, then extrapolated to the turbine site. In this case, the average density is $1.06 \mathrm{~kg} / \mathrm{m}^{3}$.

Table 4.Average wind speed of wind farm affected by wake[m/s].

\begin{tabular}{|c|c|c|c|}
\hline Direction & Shear[-] & Direction & Shear[-] \\
\hline $0^{\circ}\left(-15^{\circ}-15^{\circ}\right)$ & 0.08 & $180^{\circ}\left(165^{\circ}-195^{\circ}\right)$ & 0.08 \\
\hline $30^{\circ}\left(15^{\circ}-45^{\circ}\right)$ & 0.13 & $210^{\circ}\left(195^{\circ}-225^{\circ}\right)$ & 0.12 \\
\hline $60^{\circ}\left(45^{\circ}-75^{\circ}\right)$ & 0.21 & $240^{\circ}\left(225^{\circ}-255^{\circ}\right)$ & 0.16 \\
\hline $90^{\circ}\left(75^{\circ}-105^{\circ}\right)$ & 0.19 & $270^{\circ}\left(255^{\circ}-285^{\circ}\right)$ & 0.14 \\
\hline $120^{\circ}\left(105^{\circ}-135^{\circ}\right)$ & 0.14 & $300^{\circ}\left(285^{\circ}-315^{\circ}\right)$ & 0.11 \\
\hline $150^{\circ}\left(135^{\circ}-165^{\circ}\right)$ & 0.07 & $330^{\circ}\left(315^{\circ}-345^{\circ}\right)$ & \\
\hline Average & \multicolumn{2}{|c}{0.11} & \\
\hline
\end{tabular}

\section{Historical operation data analysis and condition evaluation}

The historical operation data of wind turbine is related to the structural load of the turbine, which is also the basis of load life assessment. Through the analysis of historical operation data, we can find typical turbines and find the concentration and batch problems in historical operation, so as to carry out further in-depth evaluation. Generally, historical SCADA data, overhaul and maintenance records, description of turbine control and communication controller are used as reference materials for operation data analysis, and the analysis 
scope covers each turbine to be evaluated. For a wind farm with a large number of turbines in the field, in order to improve the evaluation efficiency, clusters can be divided according to a unified standard (according to the turbine spacing, terrain characteristics, wake influence area, etc.), and the typical characteristics of the turbines in the cluster can be analyzed ${ }^{[9]}$.

During the operation data analysis, the transient events related to load are also concerned. The wind speed of hub height, turbine speed, control response type, cumulative operation hours and time distribution are statistically analyzed. Transient events that have significant impact on wind turbine load, such as emergency shutdown caused by triggering safety chain, normal start-up and shutdown of turbines, abnormal stop of control system, yaw error exceeding design limit, system failure, etc.

Generally, it is important to determine the operation status of the turbine after 20 years of operation. The inspection methods generally include visual inspection, oil and vibration monitoring and analysis, nondestructive testing, etc. At the same time, the pitch test, yaw test, protection performance and other functional tests of the turbine are also carried out. According to the actual needs, further physical, chemical, mechanical properties, wear, aging and other performance tests are carried out to analyze the current health status of the turbine and give the instructions for the continued operation of the wind turbine. As a basic means of visual inspection, it is necessary to carry out basic evaluation on the important key components that affect the structure and safety of the turbine, and also pay attention to the basic operation status of other components. The uncertainty introduced by inspection needs to be analyzed in further uncertainty evaluation. In this case study, the visual inspection of the turbine was carried out, covering the key components, general components and equipment subsystems of the turbine.

\section{Turbine physical model}

The physical model is the premise of wind turbine load assessment. The physical model reflects the basic characteristics of the turbine. Due to the lack of design data, the case modeling refers to the design drawings, analysis and calculation results, turbine specifications parameters, machine machinery and electrical manual, control system software and manual, certification and evaluation report of components and complete turbine, attached documents, etc. ${ }^{[10]}$. For the data which is missing or cannot be obtained directly, such as blades, the mapping and reverse method are adopted. The blade model is established by referring to other turbine design experience in the aerodynamic and structural layout of blades. The verification of physical model includes basic size, weight, power curve, wind energy utilization coefficient curve and thrust coefficient curve, power generation, airfoil data and public database. The Campbell diagram of the model is also calculated. It is verified that the natural frequency of tower/blade is higher than the working frequency that may produce resonance.

\section{Calculation and analysis of residual life of wind turbine}

The calculation and analysis of residual life of wind turbines are based on fatigue life analysis without considering extreme loads. According to the standard working conditions described in IEC61400-1, DLC1.2, DLC3.1, DLC4.1 and DLC6.4 are considered in the design load assessment, and the above load conditions are also considered in the assessment of corresponding specific site conditions. Because DLC1.2 and DLC6.4 are the main loads, only these two conditions are calculated in this case. The calculation principle is: the life extension coefficient is obtained according to the comparison of the fatigue life (allowable cycle number) of the physical model (the Bladed model) of the wind turbine at the key position (load section) under two kinds of power production and external conditions. ${ }^{[1-12]}$. Because the original design load data can not be obtained, the reference set of design fatigue load is generated by using the same physical model as the calculation of specific site load.

The following definitions are considered in the load and life analysis based on fatigue conditions:

a) External environmental conditions

Under the design conditions, the Kaimal turbulence model in IEC61400-1 is used to simulate each wind speed with different turbulence seeds.

External environment data (wind speed, wind frequency distribution parameters, turbulence intensity, wind shear coefficient, inflow angle, air density, etc.) of a specific site.

b) Turbine physical model

c) The design life of the turbine is 20 years.

d) The general coordinate system is adopted, and the position of load output section is: blade root composite material and blade root connection, hub and hub shaft connection, main shaft, main frame casting and welded, tower top and tower bottom.

e) The Wöhler coefficient of $\mathrm{S} / \mathrm{N}$ curve is usually: $\mathrm{m}=8$ for casting, $\mathrm{m}=5$ for welded and joint, $\mathrm{m}=10$ for composite.

The calculation of residual life includes the calculation of equivalent damage load (DEL) and number of cycles (n) under design conditions and specific site conditions

a) Run the simulation to obtain the load evaluation results (Time Series).

b) The selected loads of key components of wind turbine are counted and the Markov matrix is obtained.

c) When calculating the equivalent damage load (DEL), the following factors are considered:

- The calculated Markov matrix

- The frequency table of load cases

- The Wöhler parameter (reciprocal of the slope of the $\mathrm{S} / \mathrm{N}$ fatigue curve) for a specific wind turbine component 
The life extension factor (or remaining life factor) can be determined by the number of cycles allowed under the design conditions ( $\mathrm{N}$ cert) and the number of cycles allowed under specific site conditions (N_site), The ratio of site is as follows:

Remaining life factor $(\mathrm{LTE})=\left(\mathrm{N}_{-}\right.$cert $) /\left(\mathrm{N}_{\text {_ site }}\right)$

The accuracy level of life extension factor is largely affected by the quantity and quality of available data (collected from design stage and field), wind turbine model and simulation.

\section{Uncertainty analysis}

According to UL 4143 standard, RUL(remaining useful life) can be obtained by measurement and several load analysis or statistical analysis (such as analysis of SCADA data). Therefore, there is certain uncertainty in RUL determination. In this case, the uncertainty of the defined life extension factor (LTE) takes into account the uncertainty characteristics from the external environmental conditions (wind speed, turbulence intensity, wind shear, inflow angle and air density), the uncertainty factors in wind turbine modeling and turbine inspection ${ }^{[14-15] \text {. }}$

Assuming that the uncertainty of a specific site and the uncertainty of wind turbine modeling are random and independent, the overall uncertainty of life extension factor is obtained by calculating the sensitivity of each parameter. The sensitivity coefficient is obtained by the slope (the LTE coefficient changes when the given parameter changes) and is specific to each load section or component. Sensitivity is critical for many LTE uncertainties because it is inversely correlated with the Wöhler parameter $(\mathrm{m})$ on the $\mathrm{S} / \mathrm{N}$ curve. This means that a moderate change in the load level (DEL) may result in a significant change in the number of theoretical cycles.

In this case, the uncertainty of each influence factor is set as shown in Table 5 .

Table 5.Uncertainty factors of wind farm.

\begin{tabular}{|c|c|c|c|}
\hline $\begin{array}{c}\text { External } \\
\text { conditions }\end{array}$ & Uncertainty & $\begin{array}{c}\text { External } \\
\text { conditions }\end{array}$ & Uncertainty \\
\hline Wind speed & $4.03 \%$ & Inflow angle & $5.20 \%$ \\
\hline $\begin{array}{c}\text { Turbulence } \\
\text { intensity }\end{array}$ & $8.49 \%$ & $\begin{array}{c}\text { Turbine } \\
\text { inspection }\end{array}$ & $1 \%$ \\
\hline Wind shear & $26.24 \%$ & $\begin{array}{c}\text { Physical } \\
\text { model }\end{array}$ & $5.20 \%$ \\
\hline Air density & $5.27 \%$ & & \\
\hline
\end{tabular}

The sensitivity and Wöhler parameter of each load section vary with the life extension factor and wind speed distribution in each wind direction sector. Through different simulations of the same wind turbine model, different sensitivity coefficients are obtained by changing the parameters of sensitivity analysis. Each wind turbine and wind direction sector is systematically simulated at least five times to obtain the change trend (slope) of each load section. In addition, the sensitivity of the turbine model is analyzed by analyzing the influence of the input parameters on the turbine model and the influence of the input parameters on the life of the turbine components.

Each sensitivity coefficient is multiplied by the corresponding uncertainty to obtain the uncertainty of the life extension factor on each load section/component. Considering that the influence of different wind parameters on the uncertainty is independent, the total uncertainty of LTE coefficient can be obtained by multiplying them by their sensitivity coefficients. Considering the LTE coefficient and normal distribution of each component, the corresponding $\mathrm{P}$ value is obtained (considering that the $\mathrm{S} / \mathrm{N}$ curve of material characteristics is set to $97.5 \%$, and the $\mathrm{P}$ value reflects the year when the level reaches $97.5 \%$ ). The uncertainty is shown in Table6, and the P90 value of wind turbine life extension is shown in Table7.

Table 6.Calculation results of uncertainty[\%].

\begin{tabular}{|c|c|c|c|c|}
\hline Turbine & F01 & F02 & F03 & $\ldots$ \\
\hline $\begin{array}{c}\text { Blade Root. } \\
\text { Composite }\end{array}$ & 46.9 & 45.9 & 45.8 & $\ldots$ \\
\hline $\begin{array}{c}\text { Blade Root. } \\
\text { Joint }\end{array}$ & 25.1 & 24.6 & 24.5 & $\ldots$ \\
\hline Hub & 38.7 & 37.9 & 37.8 & $\ldots$ \\
\hline $\begin{array}{c}\text { Hub Shaft } \\
\text { Joint }\end{array}$ & 43.6 & 43.1 & 42.8 & $\ldots$ \\
\hline $\begin{array}{c}\text { Low Speed } \\
\text { Shaft }\end{array}$ & 59.7 & 59.3 & 58.6 & $\ldots$ \\
\hline $\begin{array}{c}\text { Main Frame } \\
\text { Casting }\end{array}$ & 65.5 & 65.2 & 64.9 & $\ldots$ \\
\hline $\begin{array}{c}\text { Main Frame } \\
\text { Welded }\end{array}$ & 53.3 & 53 & 52.7 & $\ldots$ \\
\hline Tower Top & 52.9 & 52.6 & 52.3 & $\ldots$ \\
\hline $\begin{array}{c}\text { Tower } \\
\text { Bottom }\end{array}$ & 52.8 & 53.1 & 53.3 & $\ldots$ \\
\hline
\end{tabular}

Table 7.Calculation results of residual life (P90).

\begin{tabular}{|c|c|c|c|c|}
\hline Turbine & $\mathrm{F} 01$ & $\mathrm{~F} 02$ & $\mathrm{~F} 03$ & $\ldots$ \\
\hline $\begin{array}{c}\text { Blade Root. } \\
\text { Composite }\end{array}$ & $>30$ & $>30$ & $>30$ & $\ldots$ \\
\hline $\begin{array}{c}\text { Blade Root. } \\
\text { Joint }\end{array}$ & $>30$ & $>30$ & $>30$ & $\ldots$ \\
\hline Hub & $>30$ & $>30$ & $>30$ & $\ldots$ \\
\hline $\begin{array}{c}\text { Hub Shaft } \\
\text { Joint }\end{array}$ & $>30$ & $>30$ & $>30$ & $\ldots$ \\
\hline $\begin{array}{c}\text { Low Speed } \\
\text { Shaft }\end{array}$ & $>30$ & $>30$ & $>30$ & $\ldots$ \\
\hline $\begin{array}{c}\text { Main Frame } \\
\text { Casting }\end{array}$ & $>30$ & $>30$ & $>30$ & $\ldots$ \\
\hline $\begin{array}{c}\text { Main Frame } \\
\text { Welded }\end{array}$ & $>30$ & $>30$ & $>30$ & $\ldots$ \\
\hline Tower Top & 52.9 & 52.6 & 52.3 & $\ldots$ \\
\hline $\begin{array}{c}\text { Tower } \\
\text { Bottom }\end{array}$ & 52.8 & 53.1 & 53.3 & $\ldots$ \\
\hline
\end{tabular}

\section{Conclusion}

In this paper, taking an extended service wind farm as an example, referring to the standards and guidelines, based on the specific site evaluation requirements of IEC61400-1 standard and UL 4143 standard, the remaining life and health status of 33 wind turbines are evaluated. The data of hub height and wind condition of the turbine are obtained by extrapolation, and the 
physical model of the turbine is modeled by the way of original design data aided reverse and verification. Combined with historical operation data and state inspection analysis, the remaining life of 33 turbines in the whole wind farm is obtained by load simulation and analogy, and the final P90 life is obtained by uncertainty analysis. By using the residual life and health assessment method, the comprehensive safety and reliability assessment of the turbines that have been operating for more than 20 years is carried out, which provides the basic theoretical support for the formulation of subsequent life extension or decommissioning strategies.

\section{References}

1. Zhang, W.Z., Du, W.Z.. (2020). Retiring the old and upgrading the new: the path of "extending the life" of the old wind turbines with 10 million installed capacity. Wind energy industry,08,15-17.

2. Xu, Y.P.. (2019). Economic analysis of wind turbine life extension in wind farm. Wind energy,11,74-79.

3. Delony, J.. (2018). The repowering mission: breathing new life into our aging wind turbine fleet. Renewable energy world magazine, 21(03), 18,2022.

4. Ziegler, L., Gonzalez, E., Rubert, T., Smolka, U., \& Melero, J.J.. (2018). Lifetime extension of onshore wind turbines: a review covering germany, spain, denmark, and the uk. Renewable \& Sustainable Energy Reviews, 28(1), 1261-1271.

5. Zhang, S.H., Huang, Y.L., Zhou, M.. (2016). Life extension technology and service of wind turbine and analysis of relevant standards. Wind energy, 07,74-76.

6. DNV GL. Lifetime extension of wind turbines.DNVGL-ST-0262;2016.

7. UL. Wind Turbine Generator-Life Time Extension.UL 4143;2018.

8. IEC. Wind turbines - Part 1: Design requirements. IEC 61400-1-4; 2019.

9. Rubert, T., Zorzi, G., Fusiek, G., Niewczas, P., Mcmillan, D., \& Mcalorum, J., et al. (2019). Wind turbine lifetime extension decision-making based on structural health monitoring. Renewable Energy, 143(DEC.), 611-621.

10. Amiri, A. K., Kazacoks, R., Mcmillan, D., Feucht Wa Ng, J., \& Leithead, W.. (2019). Farm-wide assessment of wind turbine lifetime extension using detailed tower model and actual operational history. Journal of Physics: Conference Series, 1222, 012034-.

11. Schedat, M., Faber, T., \& Sivanesan, A.. (2016). Structural health monitoring concept to predict the remaining lifetime of the wind turbine structure. 2016 International Conference on the Domestic Use of Energy (DUE). IEEE.
12. Mcgugan, M., \& Mckirdy, S.. (2016). Structural health monitoring tools for late and end of life management of offshore wind turbines.

13. Zhao, H.S., Li, Z.L.. (2020). Prognosis of remaining lifetime of wind turbine turbine shafting. Electric Power Automation Equipment,40(06), 70-75+99+12.

14. Huang, M., Lu, H.G., Wang, B.Q., Lu, Y.. (2015). Measurement uncertainty analysis of Ultrasonic Wind Sensor . Journal of Chengdu Institute of information engineering, 30 (04), 361-365.

15. Chen, Y., Chen, C., Liu, X.X., Shi, K.P.. (2015).Wind Power Prediction Error Based on the Uncertainty Evaluation.Power \& Energy, 36(04), 491-495. 